\title{
Allograft sternochondral replacement after resection of large sternal chondrosarcoma
}

\author{
Giuseppe Marulli, MD, ${ }^{\mathrm{a}}$ Abdel-Mohsen Hamad, MD, ${ }^{\mathrm{a}}$ Elisa Cogliati, MD, ${ }^{\mathrm{b}}$ Cristiano Breda, MD, ${ }^{\mathrm{a}}$ \\ Andrea Zuin, MD, ${ }^{\mathrm{a}}$ and Federico Rea, MD, ${ }^{\mathrm{a}}$ Padova and Treviso, Italy
}

Surgical excision with a safety margin is the cornerstone of treatment of malignant sternal tumors. After sternal resection, the primary goals of chest wall reconstruction are to prevent flail chest with ventilatory impairment, protect the underlying mediastinal structures, and avoid chest deformity. Various techniques and several materials have been used over the years for this purpose. ${ }^{1}$ This report describes the use of sternal allograft to reconstruct the chest wall after sternal resection.

\section{CLINICAL SUMMARY}

A 51-year-old patient presented with an orange-sized, painless, central anterior chest-wall mass. The mass was originally discovered 7 months before by the patient as a small palpable nodule that gradually increased in size. When the mass became more prominent, the patient sought medical advice. Ultrasound-guided needle biopsy was performed revealing a diagnosis of chondrosarcoma.

Preoperative computed tomography scan (Figure 1, A) showed a mass involving the sternal body with destruction of bony cortex and little extension to presternal soft tissue and chest wall adjacent to the left border of the sternum.

The patient underwent surgical resection. The pectoralis majors were dissected bilaterally via an elliptical incision involving the skin and soft tissue overlying the mass. Then, a full-thickness resection of the sternal body with attached costal cartilages (from third to seventh) bilaterally was performed.

The defect was reconstructed by using a cryopreserved allograft sternum with attached costal cartilages. The bone graft was harvested from a suitable donor under a complete aseptic technique and treated with antibiotic solution for 72 hours at $+4^{\circ} \mathrm{C}$ and then submitted to cryopreservation at $-80^{\circ} \mathrm{C}$. These processes guarantee the sterility of the graft

\footnotetext{
From the Department of Cardiothoracic and Vascular Sciences, University of Padova, ${ }^{a}$ Padova, Italy; and Tissues Bank of Veneto Region, Cà Foncello Hospital Treviso, ${ }^{\mathrm{b}}$ Treviso, Italy.

Disclosures: None.

Received for publication Jan 8, 2009; accepted for publication Jan 10, 2009; available ahead of print March 9, 2009.

Address for reprints: Federico Rea, MD, Department of Cardiothoracic and Vascular Sciences, University of Padova, Via Giustiniani, 2, 35128, Padova, Italy (E-mail: federico.rea@unipd.it).

J Thorac Cardiovasc Surg 2010;139:e69-70

$0022-5223 / \$ 36.00$

Copyright (c) 2010 by The American Association for Thoracic Surgery

doi:10.1016/j.jtcvs.2009.01.007
}

and the absence of immunogenic capacity (more details available at www.bancatessuti-treviso.org).

On ordering, the graft was thawed and transferred inside double sterile bags in an ice container (with this protocol the graft can be stored in refrigerator at $+4^{\circ} \mathrm{C}$ for a maximum of 1 week). At the time of use, the graft was taken out of sterile bags and washed with saline solution (Figure 1, B).

The graft was tailored to perfectly fit the defect and fixed with titanium plates and screws (Synthes, Solothurn, Switzerland) at the level of manubrium above and ribs bilaterally (Figure 1,C). The pectoralis major muscle flaps were approximated to cover the graft.

The patient was extubated in the operating room. The postoperative course was uneventful, and the patient was discharged on the seventh postoperative day. Histologic examination of the specimen confirmed the diagnosis of chondrosarcoma with moderate grade $(\mathrm{G} 2)$ of differentiation and negative resection margins.

Nine months after surgery, the patient is alive and doing well. No signs of rejection, bone necrosis, or infection were noted during follow-up (Figure 2). Magnetic resonance imaging demonstrated perfect apposition and healing of the allograft to the recipient's tissue.

\section{DISCUSSION}

Prosthetic materials are the most commonly used technique for chest wall reconstruction. ${ }^{1}$ Although these materials are widely available and easy to use, they suffer from excessive rigidity (methylmethacrylate) with erosion of adjacent structures or insufficient support (Prolene mesh); moreover, incorporation into the host tissue never occurs.

A search for the ideal material for chest wall reconstruction continues to challenge thoracic surgeons. Bone grafts have been proposed as an effective alternative to synthetic materials. The use of bone autograft (ribs or iliac bone) $)^{2,3}$ or allograft ${ }^{4}$ has been reported as a valid solution to cover small chest wall defects. The advantages of autografts are easy incorporation into the recipient bone, low risk of infection, and absent risk of rejection.

However, there is a limitation regarding the amount of bone that can be harvested and transferred to the new site, in addition to the potential complications at the donor site. Moreover, harvesting and grafting of vascularized bone are not easy.

Previous experimental and clinical experiences demonstrated that the cryopreserved bone graft retains some 

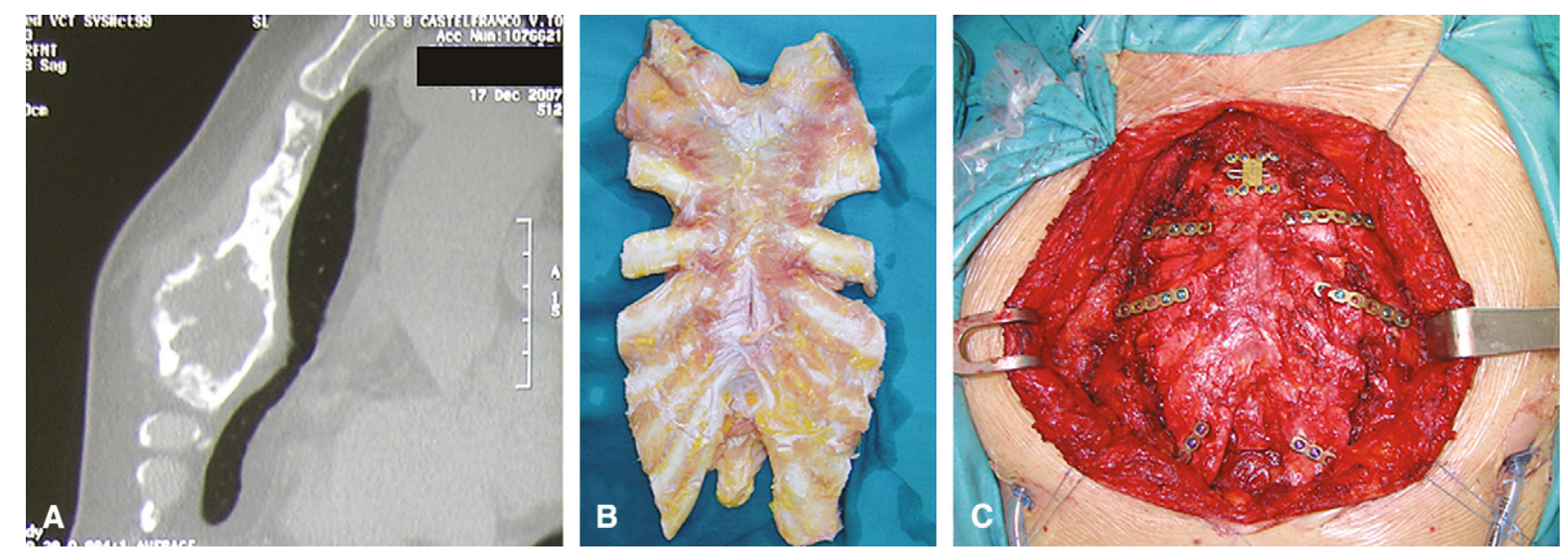

FIGURE 1. (A) Preoperative sagittal reconstruction of computed tomography scan showing the extent of the tumor (involving only the body). (B) The sternal allograft ready to be used before tailoring. (C) Intraoperative view showing the tailored sternal allograft fixed in place.
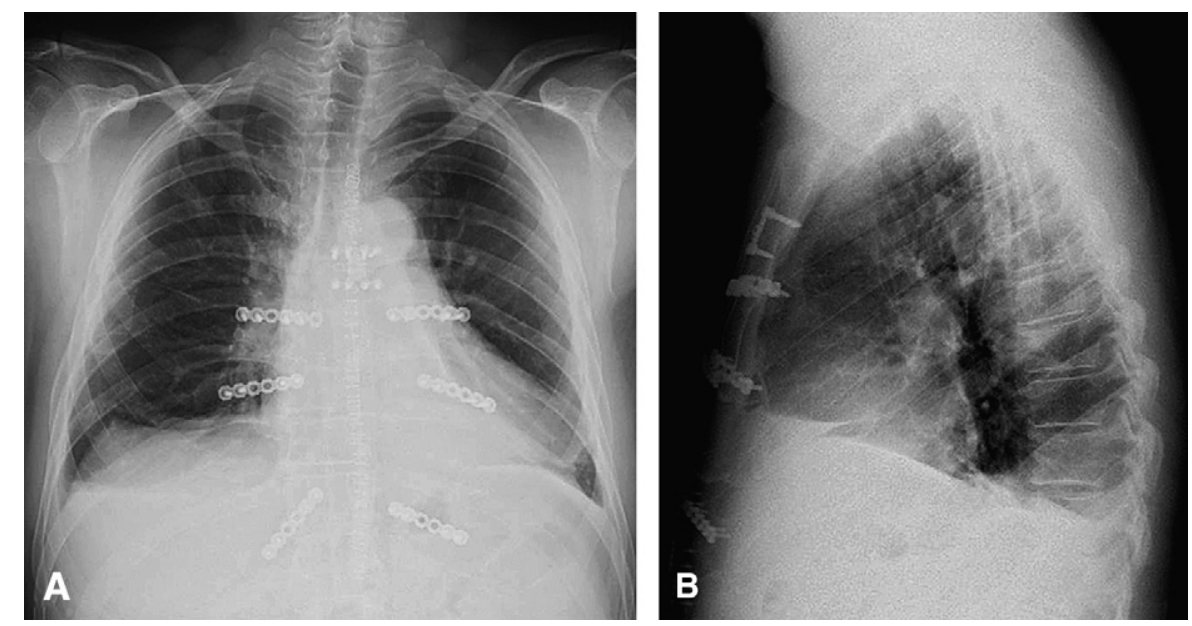

FIGURE 2. Postoperative chest $\mathrm{x}$-ray posteroanterior (A) and lateral (B) views showing proper position of the new sternum without signs of necrosis.

properties, such as osteoconductive and osteoinductive capacity. The graft acts as a scaffold for new bone formation, allowing the ingrowth of capillaries and perivascular tissue into its structure. Moreover, recruitment of undifferentiated mesenchymal cells from adjacent tissue with subsequent differentiation into osteoprogenitor cells under inductive stimulus of bone growth factors has been proved. ${ }^{5}$

To our knowledge, this is the first report of sternal replacement with allogenic cryopreserved sternum and costal cartilages. It was effective for geometrically covering the entire large anterior chest wall defect by using the same amount of bone and cartilages removed in the recipient. The use of titanium plates and screws easily permitted a perfect fixation to the bone of the host.

\section{CONCLUSIONS}

This case demonstrated that sternal allograft is an effective and biologically well-tolerated option for sternal replacement.

\section{References}

1. Arnold PG, Pairolero PC. Chest-wall reconstruction: an account of 500 consecutive patients. Plast Reconstr Surg. 1996;98:804-10.

2. Chai $Y$, Zhang G, Shen G. Autogenous rib grafts for reconstruction of sternal defects after partial resection: a new surgical technique. Plast Reconstr Surg. 2008;121:353-5.

3. Heller L, Huang WC, Chen HC, Lu CT, Lin SL. Vascularized iliac bone flap used for sternum reconstruction after resection of chondrosarcoma. Plast Reconstr Surg. 2002;110:1088-91.

4. Aranda JL, Varela G, Benito P, Juan A. Donor cryopreserved rib allografts for chest wall reconstruction. Interact Cardiovasc Thorac Surg. 2008;7:858-60.

5. Albrektsson T, Johansson C. Osteoinduction, osteoconduction and osseointegration. Eur Spine J. 2001;S10:96-101. 